MICROCAST-X FINE GRAIN CASTING - A PROGRESS REPORT

\author{
J.R. Brinegar ${ }^{1}$, L.F. Norris ${ }^{1}$, L. Rozenberg ${ }^{2}$ \\ 1 \\ Howmet Turbine Components Corporation \\ Technical Center \\ 699 Benston Road \\ Whitehall, MI 49461 \\ 2 \\ Wyman-Gordon Company \\ Research and Development \\ 244 Worchester Street \\ North Grafton, MA 01536
}

\begin{abstract}
Summary
Microcast-X is a new casting process which produces a uniformly fine grain size material (ASTM 3-5). The process, currently in development by Howmet Turbine Components Corporation, has been successfully demonstrated with components ranging from forging preforms up to $5001 \mathrm{~b}$ to turbine disks, blades and vanes. The fine grain size leads to improved uniformity in properties, chemistry and precipitate morphology compared to conventionally cast or VAR materials. Initial forging trials have been conducted by Wyman-Gordon and clearly demonstrate the excellent forgeability of Microcast-X products in comparison with conventionally cast forms. Hot die and isothermal forgings have been produced with flat dies in one and two steps with upsets up to $80 \%$ without cracking. Alloys thus far screened include Rene' 95, MERL 76, IN 718 and $\mathrm{C} 103$. Based on these results a comprehensive evaluation program has been established to characterize further the forging potential of Microcast-X material and to determine mechanical properties.
\end{abstract}


Superalloy forging preforms typically are produced from forged, rolled or extruded vacuum arc remelted (VAR) ingots or metal powder ( $P / M$ ) compacts. Direct forging of conventionally cast billets (preforms) of highly alloyed materials is difficult because of the large grain size, chemical inhomogeneity and the resultant nonuniform microstructure of the product. Howmet Turbine Components Corporation (HTCC) currently is developing the Microcast- $X^{*}$ casting process which yields a fine grain (ASTM 3-5) material with improved microstructural and chemical uniformity. This proprietary process potentially offers significant benefits by producing cast preforms and complex shapes for direct forging, thus eliminating preliminary hot working operations.

Early results from a joint HTCC and Wyman-Gordon evaluation showed excellent forgeability of Microcast-X preforms in a number of nicke1base superalloys including Rene' 95, MERL 76, C103 and IN 718. A more comprehensive program was then established to characterize the properties and microstructures of cast and forged Microcast- $X$ alloys and to provide for more extensive casting and forging parameter evaluations. Included in the casting process development activities are foundry equipment design, optimization of hot isostatic pressing (HIP) and extrusion parameters, as well as steps to maximize alloy cleanliness. Forging evaluations will examine temperatures, strain rates and intermediate heat treatments. This progress report covers the initial casting and forging experiments.

\section{Casting Evaluations}

Process evaluations and development of specialized foundry facilities are proceeding concurrently. Casting trials to date have demonstrated the versatility of the process in producing fine grain ingot and cast shapes in a wide range of sizes and configurations. Forging preforms of $3^{\prime \prime}, 6^{\prime \prime}, 8^{\prime \prime}$ and 11" in diameter with weights up to $5001 \mathrm{~b}$ have been produced. Complex shapes such as compressor blades and integral wheels also have been cast. Figure 1 shows the macrostructure of a $3001 \mathrm{~b}$ Rene' 95 preform illustrating the uniformity of the grain size throughout the cross-section.

Several cobalt-base and nickel-base alloys have been cast with significant grain refinement. Typical microstructures of six alloys are shown in Figure 2. Note that the microstructures are cellular, not dendritic. Conventional dendritic solidification of superalloys in large section sizes results in varying degrees of macrosegregation and microsegregation. As dendrites grow into the liquid, enrichment of alloying elements in the liquid ahead of the solidification front results in segregation. In contrast, cellular solidification occurs on a much finer scale which limits the potential for segregation; there is

* (The Microcast-X process is distinct from the Grainex ${ }^{\circledR}$ process now in production at HTCC. The Grainex ${ }^{\circledR}$ process produces an equiaxed grain structure in the disc of cast integral wheels, but does not result in the higher solidification rates nor the degree of structural refinement achieved with the Microcast- $\mathrm{X}$ process.) 


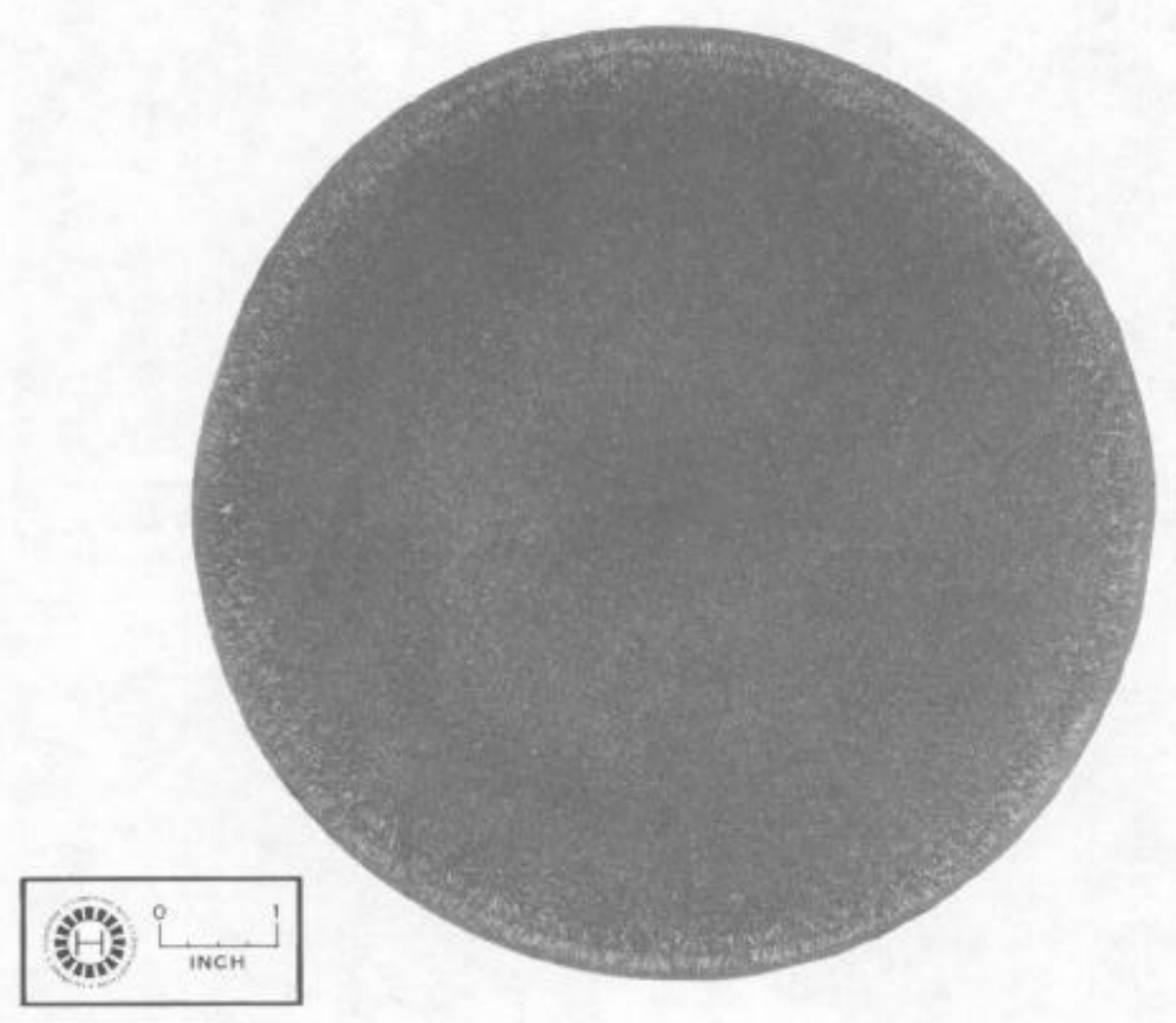

Figure 1. Macrostructure of a 300 1b, $8^{\prime \prime}$ diameter Microcast-X Rene' 95 Forging Preform.

some microsegregation but it is restricted in degree and extent by the grain (cell) size. Because of their cellular solidification, Microcast- $X$ cast products are more homogeneous than conventionally cast materials.

The size and distribution of second phase precipitates are an important consideration. The characteristics of precipitates such as carbides, borides and $\gamma-\gamma$ ' eutectic, as well as microporosity are determined by the solidification process. Small, uniformly-distributed precipitates are desirable for the control of grain growth during heat treatment and thermomechanical processing. Dendritic solidification can result in large and non-uniform precipitates leading to severe hot workability problems. Cellular solidification limits precipitate size and distribution because of the small solidification distances involved, thereby enhancing workability and the response of the alloy to thermal processing.

In the long term, existing alloy compositions may require some fine tuning to take full advantage of the Microcast-X process. Historical$1 y$, such optimization is frequently done when there is a significant change in the solidification process. Examples are directional solidification which has a very slow solidification rate and powder products which involve very rapid solidification. A greater understanding of the effect of the Microcast-X process on current alloy microstructures will be required to determine if such undertakings are necessary. 


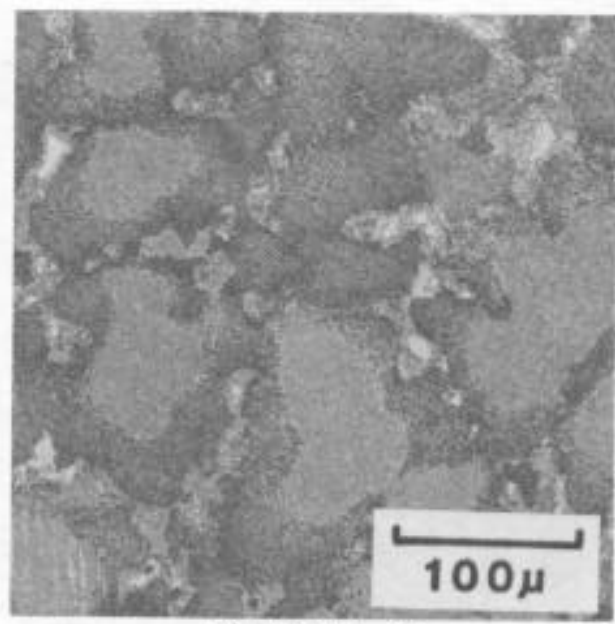

a) Rene' 95

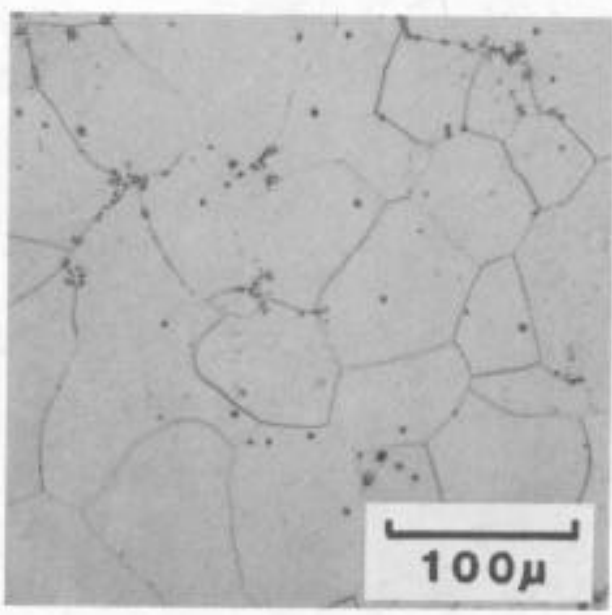

c) IN 718

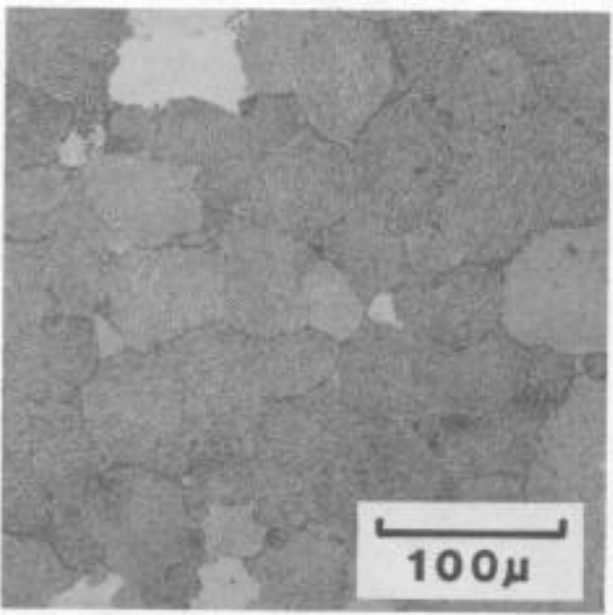

e) IN 713

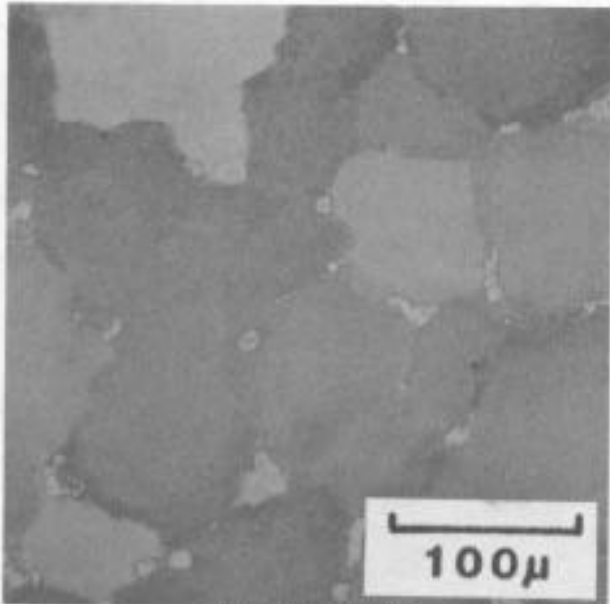

b) MERL 76

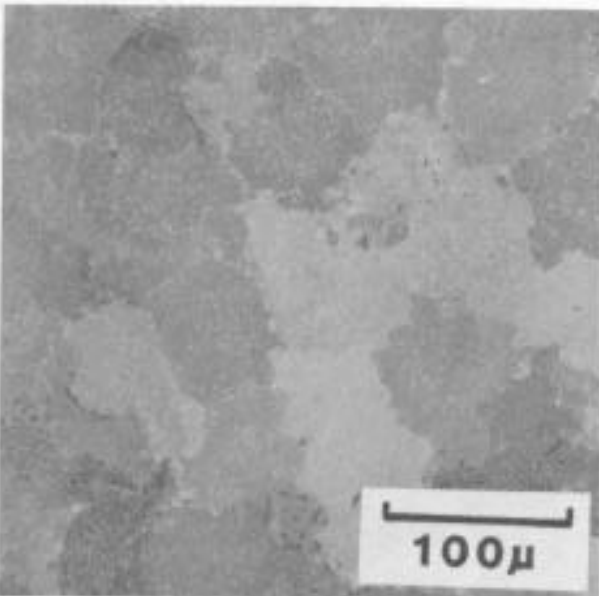

d) $\mathrm{Cl03}$

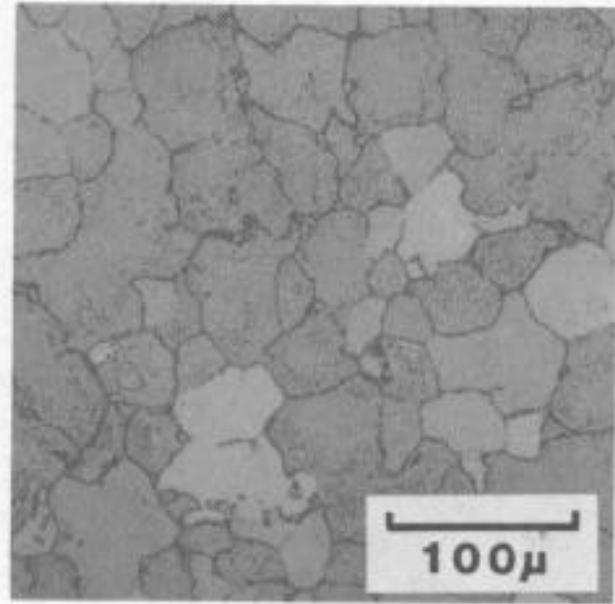

f) GMR 235

Figure 2. Microstructures of six Microcast-X cast alloys in the as-HIP'ed condition. Microstructures are from 3" diameter preforms except IN 713 and GMR 235 which are from smal1 castings. 
Due to the rapid solidification rate achieved with the Microcast-X process shrinkage porosity in the casting cannot be avoided. A consolidation process such as HIP or extrusion is required to achieve complete closure of all porosity. Initial work has shown the HIP temperature window is small and that tighter control of the entire HIP process may be required. If the temperature is too high, grain growth occurs and if too low, closure is not achieved. The role of section size is being evaluated in conjunction with time, temperature and pressure to confirm optimum HIP parameters.

Previous work by HTCC has shown that extrusion of Grainex ${ }^{(}$-cast Rene' 95 billets yields an as-extruded grain size of ASTM 10-12. This material possesses excellent forgeability. However, it does not have an optimum microstructure for subsequent thermomechanical processing because the larger as-cast dendritic grain size results in banding of carbides and $\gamma^{\prime}$ eutectic. An evaluation of extruded Microcast-X billets (which have a finer cast grain size) is in progress as an alternative to the direct forging of Microcast-X preforms, when greater workability and microstructural refinement may be required.

\section{Forging Evaluations}

Forging trials were conducted on four alloys (Rene' 95, Mer1 76, IN 718 and C103) utilizing a 1500 ton press with hot dies and a 200 ton isothermal press. All work was carried out on flat dies. Differential Thermal Analysis (DTA) was used to determine the $Y$ ' solvus temperature of the alloys to select the forging temperatures. Since forging routes varied according to alloy type and preform size, it is useful to examine the results on an individual basis.

RENF' 95

From a single billet section (1 3/4" $\emptyset \times 43 / 4$ " high) two preforms were cut for isothermal forging on the 200 ton press with flat TZM dies. The as-received (HIP'ed) microstructure had a grain/cell size of ASTM 4 and is shown in Figure 2a. An acicular phase was present with a greater amount in the center than near the edge. Although not deleterious to forgeability, this phase (tentatively identified as niobium-rich eta) was not eliminated during forging or subsequent heat treatment. Final judgement on its effects must wait until more extensive mechanical property data are obtained.

Two preforms were forged initially to a $50 \%$ upset at $2050 \mathrm{~F}$ with strain rates of $0.1 /$ minute or $0.5 /$ minute. No visual indications of cracking were noted. The partially-upset pancakes were given a recrystallization/ $\gamma^{\prime}$ overage heat treatment prior to final forging (2100F/2h, furnace cooling at 50F/h to $2000 \mathrm{~F}$, air cool). The intermediate treatment was beneficial to forgeability, lowering the flow stress as much as 25\% (from 13 to $10 \mathrm{ksi}$ ) during the finish forging operation.

The final forging aimed for an $80 \%$ overall deformation, utilizing the same forging temperature and strain rates as the first upset (Figure $3 a)$. No cracking was encountered and flow stresses were low, clearly demonstrating the forgeability of this material. Finish forged 


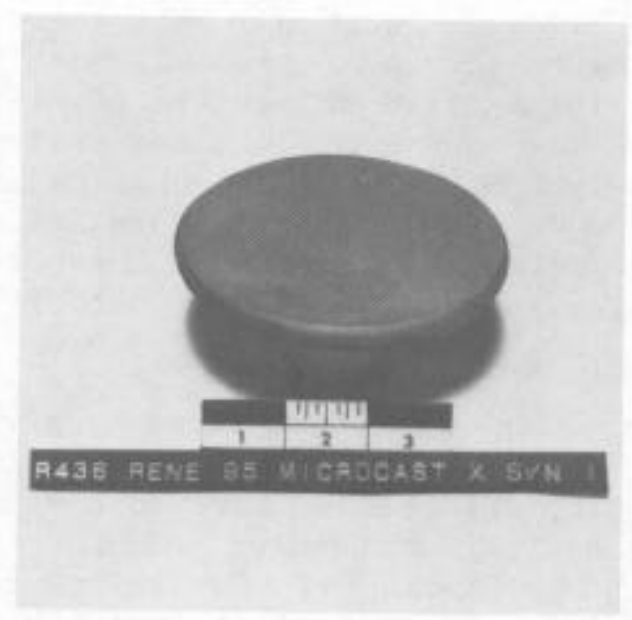

a)

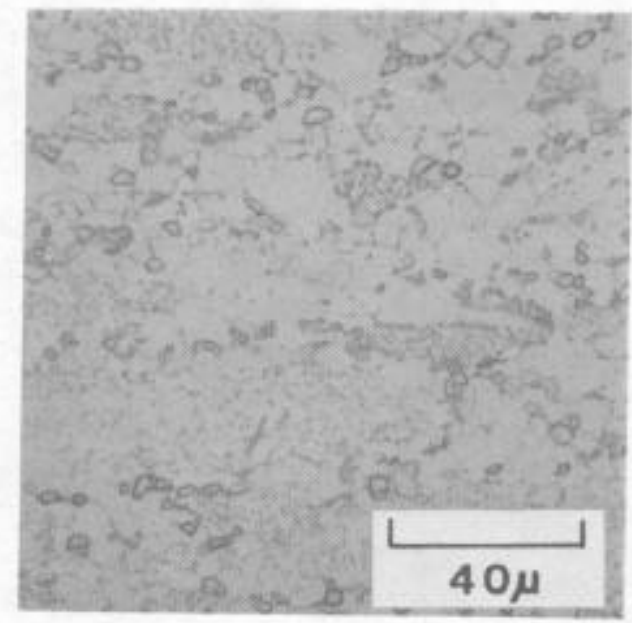

c)

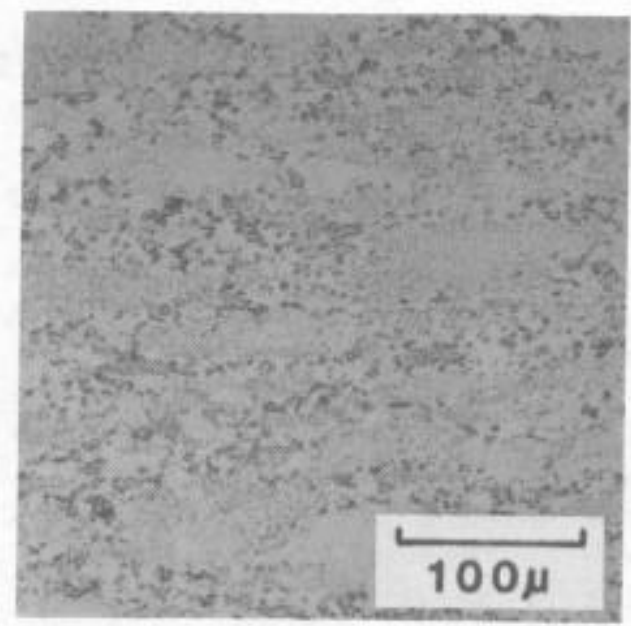

b)

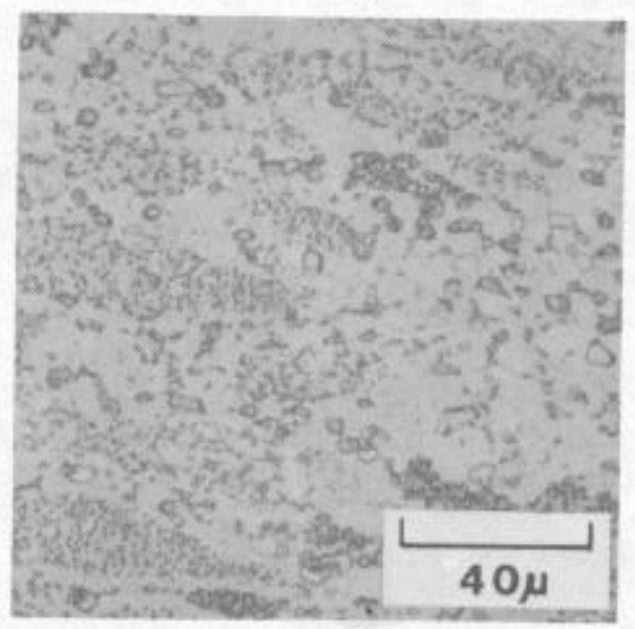

d)

Figure 3. Photomacrograph of an $80 \%$ upset isothermally forged Microcast $-X$ preform (a), the as-forged (b) and (c) and the forged and heat treated microstructures (d).

microstructures are shown in Figures $3 b$ and $c$. These show a duplex structure comprising a recrystallized grain boundary necklace with a grain size of ASTM 10 or finer surrounding partially deformed, unrecrystallized "original" grains of approximately ASTM 4-5. After forging, the pancakes were given a standard sub-solvus heat treatment (2050F/1h/oil quench; 1600F/1h/air cool; 1200F/24h/air coo1). A typical heat treated microstructure is shown in Figure $3 \mathrm{~d}$. There appears to be a slight increase in the number of recrystallized grains compared to the as-forged structure. Uniformity of microstructure through the crosssections was good with only a minimal unworked surface layer at the center of each pancake.

An attempt to forge large (up to $8 " \emptyset$ ) preforms is planned to determine the extent of forgeability utilizing the forging/heat treat parameters developed in this study. 


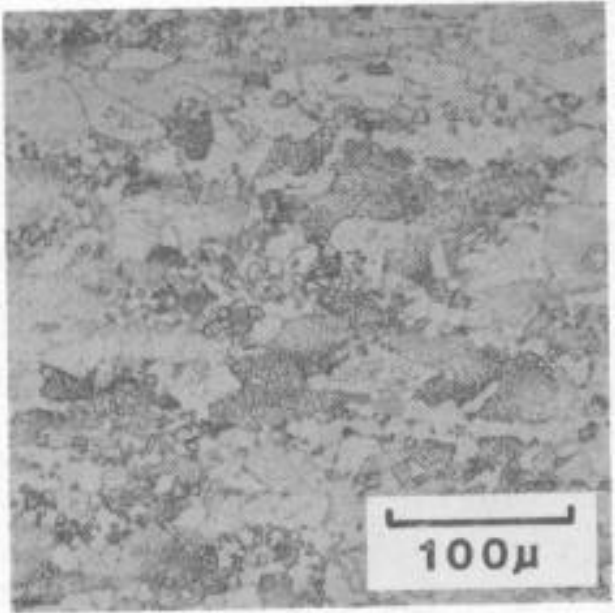

a)

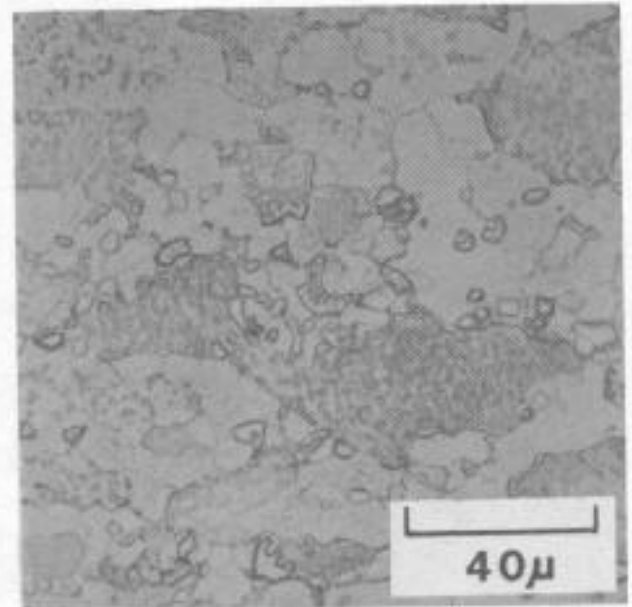

b)

Figure 4. Microstructure of a two step ( $40 \%$ initial $60 \%$ tota1) isothermally forged and heat treated Microcast-X MERL 76 preform.

MERL 76

Two preforms with an as-recelved grain size of ASTM 3 (Figure 2b) were forged on the 200 ton isothermal press utilizing flat dies. The two preforms, both from the same ingot, were $2.8 D \times 3.4^{\prime \prime}$ high. The alm was a $60 \%$ total upset to be carried out in two forging steps. The initial forge step was at $2100 \mathrm{~F}$ and a strain rate of $0.1 /$ minute with aims of $20 \%$ and $40 \%$ upsets, respectively, for the two preforms.

Flow stresses encountered were somewhat higher (14-15 ksi) than those for the Rene' 95 material. The $40 \%$ upset pancake had a few minor indications present on the circumference. The indications were removed by touch-up grinding. Both pancakes were given an intermediate heat treatment (2150F/2h/furnace cool at $50 \mathrm{~F} / \mathrm{h}$ to $2050 \mathrm{~F} / \mathrm{fan} \mathrm{cool}$ ) to promote $\gamma^{\prime}$ overaging/recrystallization prior to final forging. The heat treatment reduced the flow stress in the second forging step by up to $50 \%$. Flow stresses were approximately equal to those experienced with Rene' 95 during the finish operation (7-10 ksi). Deformation was $60 \%$ overall with the forge temperature and strain rate remaining the same as in the initial upset for both pancakes. No indications were noted following the final upset.

A comparison of microstructures between the two pancake forgings did not reveal any major differences in the amount of recrystallization or secondary phases following final upset. It would appear that in the deformation range studied the cumulative amount of work is more significant than the individual steps.

The forged and heat treated $(2090 \mathrm{~F} / 2 \mathrm{~h} /$ oil quench; $1800 \mathrm{~F} / \mathrm{lh} / \mathrm{fan} \mathrm{coo} 1$; $1350 \mathrm{~F} / 8 \mathrm{~h} / \mathrm{air} \mathrm{cool}$ ) microstructures of a MERL 76 preform are shown in Figure 4. The structure consists of a fine grain boundary necklace and 
TABLE I

Average Tensile and Rupture Properties of Microcast-X MERL 76 Heat Treatment: $2090 \mathrm{~F} / 2 \mathrm{~h} / \mathrm{OQ}+1800 \mathrm{~F} / 1 \mathrm{~h} / \mathrm{AC}+1350 \mathrm{~F} / 8 \mathrm{~h} / \mathrm{AC}$

\begin{tabular}{|c|c|c|c|c|c|c|c|c|c|}
\hline Condition & $\begin{array}{l}\text { No.of } \\
\text { Tests }\end{array}$ & $\begin{array}{l}\text { Test } \\
\text { Type }\end{array}$ & $\begin{array}{l}\text { Temp } \\
\left({ }^{\circ} \mathrm{F}\right)\end{array}$ & $\begin{array}{l}\text { Stress } \\
\text { (ksi) }\end{array}$ & $\begin{array}{l}\text { Life } \\
(\mathrm{h})\end{array}$ & $\begin{array}{r}\text { UTS } \\
(\mathrm{ksi})\end{array}$ & $\begin{array}{c}\text { YS } \\
\text { (ksi) }\end{array}$ & $\begin{array}{l}E L \\
(\%)\end{array}$ & $\begin{array}{l}\mathrm{RA} \\
(\%)\end{array}$ \\
\hline Cast & 2 & TN & RT & & & 182 & 128 & 15.0 & 17.2 \\
\hline Forged & 4 & $\mathrm{TN}$ & RT & & & 213 & 151 & 22.0 & 22.4 \\
\hline Cast & 2 & TN & 900 & & & 178 & 139 & 15.0 & 15.4 \\
\hline Forged & 4 & $\mathrm{TN}$ & 1150 & & & 202 & 151 & 21.4 & 23.4 \\
\hline Cast & 2 & $\mathrm{TN}$ & 1200 & & & 175 & 136 & 16.0 & 19.5 \\
\hline Forged & 4 & $\mathrm{SR}$ & 1350 & 95 & 172.0 & & & 19.2 & \\
\hline Cast & 2 & $S R$ & 1350 & 115 & 18.3 & & & 5.8 & 8.3 \\
\hline Cast & 2 & SR & 1350 & 130 & 1.2 & & & 4.9 & 7.4 \\
\hline
\end{tabular}

larger, unrecrystallized partially-deformed grains similar to the Rene' 95 structure. The degree of recrystallization was somewhat lower than with the Rene' 95 and this may account for the higher flow stress initially encountered.

Uniformity through the cross-section was excellent with little discernible unworked material at the center surface. The carbides appeared somewhat coarser in the MERL 76 compared to Rene' 95.

The results of the initial tensile and rupture testing are shown in Table 1. Testing of the cast and the forged specimens was conducted at different parameters. However, it can be seen that the isothermal forging improves both strength and ductility. No difference in properties between the two forgings ( 20 and $40 \%$ initial upsets) was observed.

$\underline{\text { IN } 718}$

From half of a cylindrical section ( $53 / 4 " \emptyset \times 2$ " high) two pie-shaped preforms were cut and prepared for hot die forging on the 1500 ton press with flat dies. Chemical analysis and microstructural evaluation of the as-received material showed the presence of Laves phase, delta phase, and titanium and niobium carbides. One of the two preforms then received a homogenization heat treatment $(2125 \mathrm{~F} / 2 \mathrm{~h} ; 2150 \mathrm{~F} / 2 \mathrm{~h} / \mathrm{air}$ cool) prior to forging. Microstructural examination showed this treatment solutioned both the Laves and delta phases. Final preparation for forging included preform grinding to remove sharp edges, shot blasting and coating with a lubricant. Forging to the aim of $70 \%$ upset was carried out in one step utilizing a constant crosshead speed of $5 \%$ /minute. Die temperature was $1650 \mathrm{~F}$ and preform temperature was $1850 \mathrm{~F}$. Both pancakes were water quenched off the press and subsequently received a conventional aging treatment $(1325 \mathrm{~F} / 8 \mathrm{~h} /$ furnace $c 001$ at $100 \mathrm{~F} / \mathrm{h}$ to $1150 \mathrm{~F} / 8 \mathrm{~h} / \mathrm{air}$ cool). Forgeability of both preforms was excellent with low flow stresses and no apparent cracking. 


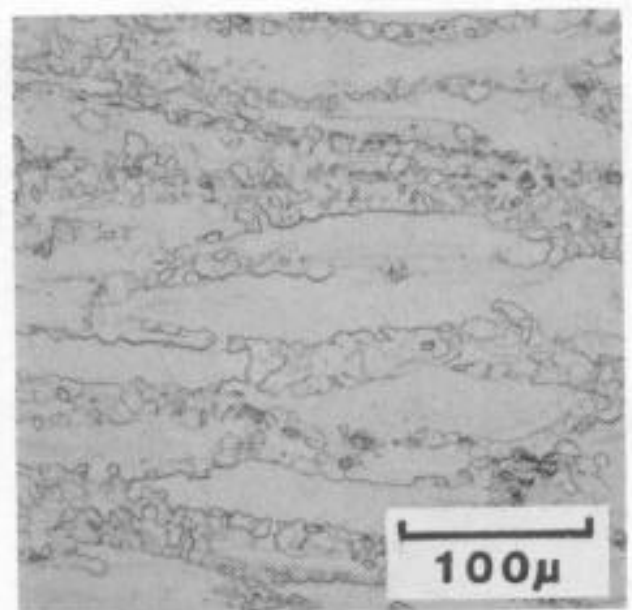

a)

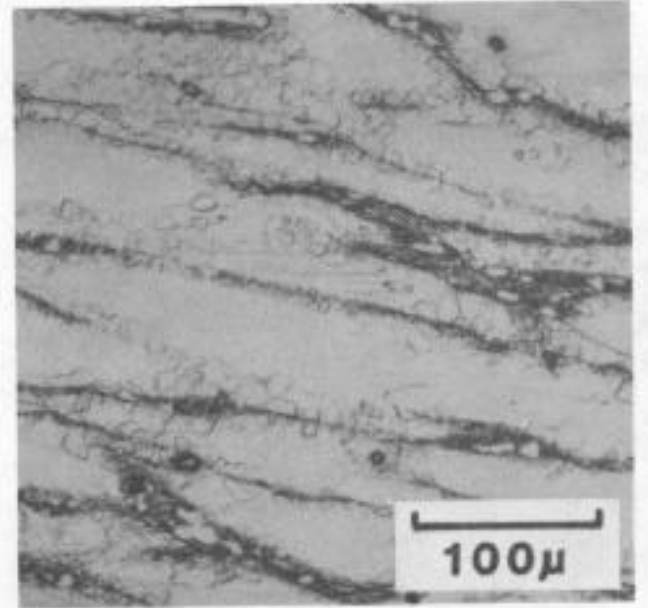

b)

Figure 5. Microstructures of two $70 \%$ upset hot die forged Microcast-X IN 718 preforms, a) homogenized prior to forging; b) not homogenized prior to forging; note delta phase at the prior grain boundaries.

The as-forged microstructures are presented in Figure 5. For both the homogenized and unhomogenized cases, the microstructure consisted of a duplex grain size with a necklace of grains ASTM 10 or finer and unrecrystallized grains about ASTM 4. This may be compared to the material in Figure $2 c$ which had been homogenized prior to forging. Here the initial grain size was in the ASTM 3-4 range. A comparison of the microstructures shows the heavy delta precipitation at the grain boundaries for the unhomogenized pancake.

Overall macrostructural uniformity was very good with few areas of unworked material present.

\section{$\mathrm{C} 103$}

Five preforms were isothermally forged on the 200 ton press utilizing flat dies to upsets ranging from 10 to $80 \%$. All starting preforms were obtained from one ingot and were $21 / 2^{\prime \prime}$ in diameter with heights corresponding to the degree of deformation desired. All forging was carried out in one step at $2050 \mathrm{~F}$ with a strain rate of $0.1 /$ minute.

All preforms forged well without any apparent cracking. The flow stress, however, was the highest of the four alloys forged (ranging from 20 to $26 \mathrm{ksi}$ ). An example of the $80 \%$ upset as-forged microstructure is shown in Figure. A duplex structure was again observed but with the least amount of recrystallization of the four alloys examined. The starting microstructure is shown in Figure $2 \mathrm{~d}$.

Recrystallization was not seen in this alloy for the tested preform size until upsets of $60 \%$ or greater were achieved. To increase the degree of recrystallization a two step forging practice with an intermediate $\gamma^{\prime}$ overage/ recrystallization heat treatment may be required. 


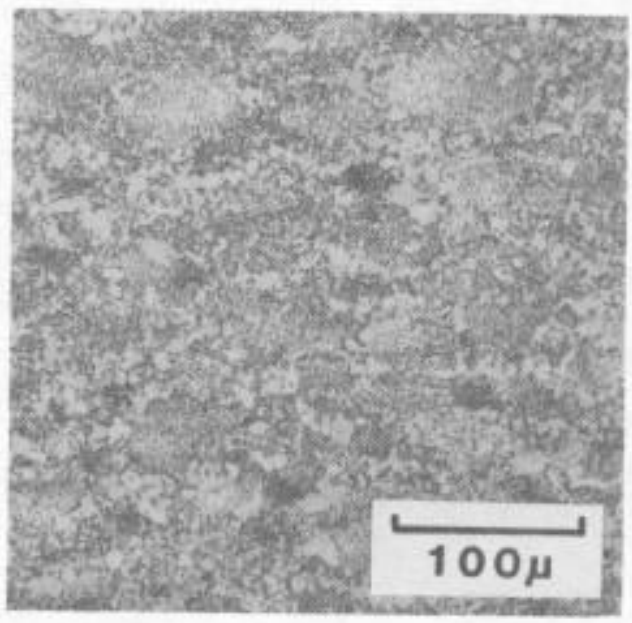

a)

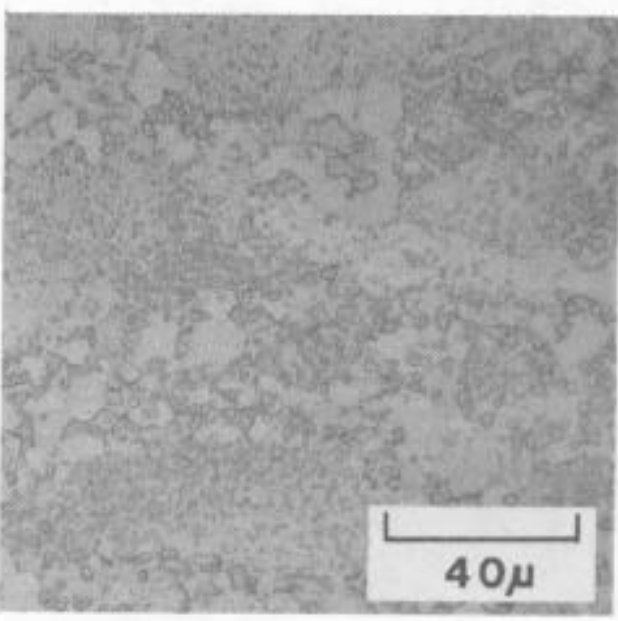

b)

Figure 6. Microstructure of $80 \%$ upset isothermally forged $\mathrm{C} 103$ Microcast-X preform.

The heat treated microstructure $(2150 \mathrm{~F} / 2 \mathrm{~h} / \mathrm{air}$ coo $1 ; 1550 \mathrm{~F} / 4 \mathrm{~h} / \mathrm{air}$ coo 1 and $1400 \mathrm{~F} / 16 \mathrm{~h} / \mathrm{air}$ cool) was not discernibly different in the degree of recrystallization than the as-forged structure for any of the upsets studied. Cross-sectional uniformity was very good for the more heavily upset pancakes with no unworked areas present except for the center surface.

\section{Concluding Remarks}

These preliminary evaluations indicate the potential of the Microcast-X process for producing directly forgeable preforms. Several alloys of commercial interest (Rene' 95, MERL 76, IN 718 and C103) have been isothermally and hot die forged successfully with upsets to $80 \%$. A more comprehensive program is underway by both Wyman-Gordon and Howmet Turbine Components Corporation to develop and refine casting and forging parameters, casting equipment design, HIP and extrusion parameters and process economics. 